\title{
The Application of the IMB Model as Primary Prevention on Adolescent's Premarital Sexual Intention
}

\author{
Linda Suwarni, Selviana, Ufi Ruhama, Iskandar Arfan \\ Department of Public Health Science, Universitas Muhammadyah Pontianak, Indonesia
}

\begin{abstract}
Article Info
Article history:

Received Dec 06, 2016

Revised Jan 27, 2017

Accepted Feb 15, 2017

\section{Keyword:}

Information

Motivation

Behavior Skill

Adolescence

Primary Prevention

ABSTRACT

Previous studies showed the information, motivation, and behavioral skills (IMB) model could be used to predict and prevent reducing sexual risk behaviors. This paper examines the effectiveness of IMB interventions in reducing adolescent's premarital sexual intentions. A quasy experimental nonequivalent pretest-posttest control group design was conducted among 250 students in 20 secondary schools in Pontianak with intervention IMB models and 100 students in the control group. There was a significant differences of information (delta mean $=3.008 ; 95 \% \mathrm{CI}=2.329$ to $3.687 ; \mathrm{p}$ value $=0.0001)$, motivation (delta mean $=1.532 ; 95 \% \mathrm{CI}=0.846$ to $2.218 ; \mathrm{p}$ value $=0,0001$ ), and skills to refuse or delay premarital sexual behavior $($ delta mean $=1.604 ; 95 \% \mathrm{CI}=0.629$ to $2.579 ; \mathrm{p}$ value $=0.001)$ on adolescents between before and after the application of the IMB model in secondary students in pontianak, Indonesia. In addition, there were significant differences intention adolescents in the control group and the experimental between before and after the IMB intervention ( $\mathrm{p}$ value $<0.05$ ). IMB model could be applied as primary prevention on adolescent's premarital sexual intention through integration in school subjects. It is needed a support and debriefing skills in teachers.
\end{abstract}

Copyright $@ 2017$ Institute of Advanced Engineering and Science. All rights reserved.

Corresponding Author:

Linda Suwarni,

Department of Public Health Science,

Universitas Muhammadiyah Pontianak,

A. Yani Street Number 111 Pontianak, West Kalimantan, Indonesia.

Email: lienharis@yahoo.co.id

\section{INTRODUCTION}

Approximately $1 \%$ of boy and $4 \%$ of girl population across Indonesia have a sex before they are 13 years old and some of them had a sex under 10 years old. It is reported that $4 \%$ adolescent aged 13 to 14 years old have had a sex and this percentage will increase along with the age [1]. Adolescent's premarital sexual behavior trends are encouraging (e.g., age at first sex, teen pregnancy) [2]. Premarital sexual behavior have an impact on adolescents, which involving the biological aspect (STIs (sexually transmitted infections)), unwanted pregnancy, abortion, social life rejection (drop outs/ DO) and live in poverty because of low education) and psychological aspect (loss of confidence, feeling guilty, and fear of social judgment). In this case, the girls receive a more severe impact than the men [3]-[8].

The IMB model has been tested for applicability in research on HIV prevention in resource-limited settings. Also, the IMB offers evidence of efficacy in increasing HIV preventive behavior among adolescents [9]-[12]. According to the IMB model, premarital sexual preventive behavior is influenced by: 1) information about sexuality and the risky, 2) motivation to consistently do not engage in risky behaviors, and behavioral skills to correctly refuse the risky behaviors. The effects of information and motivation on onset and sustainability of one's premarital sexual preventive behavior are mediated by behavioral skills. For example, improving one's motivation to do not engage in risky behaviors is expected to lead to an increase 
the behavioral skills to refuse the invitation premarital sexual, which then leads to an decrease in engagement of premarital sexual behavior.

IMB (Information-motivation-Behavioral Skill) theory model can be used to give the information about the preventive adolescent risk behavior depending on the school based intervention. The IMB modelframework are widely used in health promotion related to sexual and reproductive behavior risk [13]. The application of IMB is intended to improve the information and motivation of adolescents related to the sexuality in order to improve the adolescent skill in refusing to do the premarital sex. In addition, it is the strategy to realize the early premarital sex prevention behaviors among adolescents.

The IMB model was developed by Fisher and his colleagues held that HIV prevention information, motivation, and behavioral skills are the fundamental determinants of HIV preventive behavior [14]. This model has been tested of good fitness in many studies of STI/AIDS preventions among risk population recently [15]-[17]. The IMB model assumed that an individual must be well-informed, motivated and possesses the self-efficacy behavioral skills to decreases risk behaviors. The constructs of the IMB model and the relationships among them had been well-supported across HIV risk populations and health promotion behaviors; however, little work had been done in reducing premarital sex intentions among the students of junior high school, especially in Indonesia.

\section{RESEARCH METHOD}

It was a quantitative approach with quasy experimental nonequivalent pretest-posttest control group design. There are total of 250 students in 20 secondary schools in Pontianak with intervention IMB models (information, motivation, and behavioral skills) and 100 students in the control group. The participants in this research were the junior high school students in Pontianak, Indonesia. Theay are selected from 20 schools in Pontianak city, West Pontianak, Southeast Pontianak, and South Pontianak. The control group were the junior high school students in East Pontianak and North Pontianak. The intervention and control group were chosen according to the participants' location and characteristics aimed to compare the groups. Controlling for disturbing variable was done using age and sex matching. Besides, the school as the control variable locates far away from intervention group. It has not been given the information about premarital sex through training, workshop, or other information since the research done.

The group intervention had been applied IMB intervention for a month (4 sessions, 40 minutes per session). The evaluation was done before and after the intervention. The participants were asked to answer the self-reported question. This method was also applied in control group. After collecting the data, the data was analyzed using paired t-test to compare the information, motivation, and skill among before and after IMB intervention model applied. Besides, it was also done the unpaired t-test to compare the premarital behavior intention among control and experiment group.

\section{RESULTS AND ANALYSIS}

IMB training for the junior high school teacher was held in 20 junior high schools in Pontianak. The participants were chosen using proportional and random to represent the condition in Pontianak. The control group was the junior high school students in East Pontianak and North Pontianak. It was chosen because the East Pontianak district and North Pontianak district located far away from the other districts.

After socialization and training of junior high school teachers in Pontianak, the teachers educated their seventh grade students about IMB. It was done in four meetings (40 minutes per meeting). The media used in IMB was "adolescence and puberty" comics and short movies, besides the students' worksheet. The comparison of information, motivation and skill means before and after the use of IMB model to the students of Junior High School in Pontianak are presented in Table 1.

Table 1. The Information, Motivation and Behavior Skill Mean Score before and after IMB Intervention

\begin{tabular}{cccccc}
\hline & & Mean & $\mathrm{N}$ & $\begin{array}{c}\text { Standard } \\
\text { deviation }\end{array}$ & $\mathrm{p}$ value \\
\hline \multirow{2}{*}{ Information } & Prestest & 11.30 & 250 & 0.404 & 0.0001 \\
& Posttest & 14.31 & 250 & 0.493 & 0.407 \\
\multirow{2}{*}{ Motivation } & Prestest & 38.47 & 250 & 0.415 & 0.0001 \\
& Posttest & 40.00 & 250 & 0.558 & 0.0010 \\
\hline \multirow{2}{*}{ Skill } & Prestest & 48.47 & 250 & 0.593 & \\
& Posttest & 50.08 & 250 & & \\
\hline
\end{tabular}

IJPHS Vol. 6, No. 1, March $2017: 57-62$ 
Table 1 showes that mean score of pretest and posttest information of junior high school students have increased 3,008. The comparative test was used to measure the increase of adolescence's information significantly. According to the paired t-test, it was known that p-value of pretest-posttest was 0,0001 (less than 0.05). It showed that there was the significant difference about junior high school students' information before and after IMB socialization.

The mean score of motivation had increased 1.532. The comparative test was used to measure the increase of adolescence's motivation significantly before and after IMB model intervention. According to the paired T-test, it was showed that p-value of motivation pretest and posttest was 0.0001 (less than 0.05). It showed that there was the significant difference about junior high school students' motivation before and after IMB socialization.

The mean score of skill had increased 1.604. The comparative test was used to measure the increase of adolescence's skill significantly before and after IMB model intervention. According to the paired T-test, it was showed that p-value of skill pretest and posttest was 0.0001 (less than 0.05). It showed that there was the significant difference about junior high school students' skill before and after IMB socialization.

The effectivity of IMB model to the adolescence premarital sex behavior can be seen from the mean score of intensity before and after IMB intervention. The comparison of intense score before and after IMB intervention.

Table 2 showes that the decrease intention of adolescence to do premarital sex was 0.228 . The paired t-test resulted p-value was 0.0010 (less than 0.05), Ho was rejected. The result showed that there was significant adolescence's intense before and after IMB intervention. In conclusion, IMB intervention was effective to lower the intention to do premarital sex behavior.

Table 2. The Mean Score of Adolescent's Intention before and after IMB Intervention

\begin{tabular}{cccccc}
\hline & & Mean & $\mathrm{N}$ & $\begin{array}{c}\text { Standard } \\
\text { deviation }\end{array}$ & $\mathrm{p}$ value \\
\hline \multirow{2}{*}{ Intention } & Pretest & 0.90 & 250 & 0.094 & 0 \\
& Posttest & 0.68 & 250 & 0.070 & \\
\hline
\end{tabular}

The comparison of intention between the IMB intervention group and control group can be seen as follow. Table 3 informs that there was the significant premarital sex intensity of intervention group and control group ( $\mathrm{p}$ value less than 0.05). It can be concluded that IMB intervention was effective to reduce the intention to do premarital sex. IMB intervention can be used as the primary prevention to the adolescence premarital sex intention.

Table 3. The mean score of adolescence intention before and after IMB intervention

\begin{tabular}{ccccc}
\hline & $\begin{array}{c}\text { Mean gain } \\
\text { score }\end{array}$ & $\mathrm{N}$ & $\begin{array}{c}\text { Standard } \\
\text { deviation }\end{array}$ & $\mathrm{p}$ value \\
\hline Intervention Group & -0.2124 & 250 & 1.095 & 0.007 \\
Control Group & 0.2143 & 70 & 1.284 & 0.00 \\
\hline
\end{tabular}

The result showed that IMB (information, motivation, and behavioral skill) intervention of adolescence improved significantly to the adolescence's information about reproductive health (sexuality), adolescence motivation not to engage the premarital sex, and adolescence skill to refuse in doing premarital sex. The finding of this research is suitable to the research done by Bazargan et.al (2010), which resulted that IMB model could improve the skill and attitude about sexual behavior, motivation and skill in refusing to do the sex, and related significantly to the lower of sex behavior risk [18]. The result of the research also showed that IMB intervention significantly predicting the adolescence sex behavior intention (the increase of positive sexual behavior intention).

Moreover, research done by Bahrami and Zarani (2015) showed the perception about the risk of HIV and AIDS infection significantly related to the sexual behavior. The perception about the risk became the consideration to modify the sexual behavior (from risky sexual behavior to the positive behavior) [19]. Sex education in the school could lower the intention of risky sexual behavior of adolescence [20]. The school-based intervention through IMB could improve the adolescence's intention to refuse in doing premarital sex. It took a long term and sustainability of school-based intervention to give positive impact on adolescence behavior. The intervention program in early adolescence should focus more on establishing and maintaining the behavior skill which was started by improving the information and motivation on behavior, 
thus it could suppress and reduce the pressure from adolescence. In conclusion, IMB intervention could become primary prevention to the adolescence premarital sex behavior.

Children sex education was the responsibility of the parents (education in family), while the school became the secondary sex education. The role of school in giving the sex education could be understood as the secondary information to educate the children about sexuality. The purpose of sex education in the school was to understand the sexuality as the part of the essence and normal live [21].

Related to the research done by Paul-Ebhohimen, school-based intervention was to prevent the sexual transmitted infection and HIV in sub-Saharan Africa which was statistically significant to the changing of information and behavior about the sexual transmitted infection, while the intention and behavior not to do the risky behavior was more difficult to change. It was because the intention and abstinently behavior changing and the use of condom were influenced by the sexual experience before intervention [22]. The role of school was needed to prevent the sexual transmitted infection and HIV on adolescence.

According to review systematics done by Mason-Jason, et al. showed that the role of school in adolescence health reproduction service and mental health were needed to have the good character of adolescence as the next generation [23]. Besides the family environment, the school environment was also needed in supporting the adolescence to have the health behavior and refuse to have the premarital sex.

It was also said in the study conducted by De La rue, et al. that the preventive program had an impact on the adolescence information and behavior about the violence in relationship. The adolescence who had been given the intervention were significantly positive impact on their information and behavior about the violence in relationship. However, it has not showed the positive impact to the adolescence behavior, thus it was needed the modification in intervention and giving the additional skill in order to change the behavior [24]. The result also showed that the adolescence who had been given the intervention were significantly positive impact on their information and behavior to refuse the premarital sex. On the other hand, there was the improvement of the skill in refusing to do the premarital sex.

IMB model in this research was according to the needed and adolescence-based. Denno et al. (2014) said that the program which improved the access on reproduction health service was effective using adolescence-based approach [25]. IMB intervention which has applied to the teacher by the teacher more focused on the adolescence. The activities in IMB model involved the role of the adolescence more active than the teacher (facilitator) role. It could give the information about sexuality for the adolescence to improve their information, then it was also supposed to improve the adolescence motivation for not doing the premarital sex behavior and finally it could improve their skill to refuse the premarital sex.

The school-based on sexual education had the foundation to prevent HIV to the adolescence to prevent and decrease HIV cases. The result of meta-analysis showed that school-based sex education significantly improved the information about HIV (95\% CI $=0,49-0,78, p<0,001)$, self-efficacy to use condom and refuse to have premarital sex $(95 \% \mathrm{CI}=0,14-0,36, p<0,001)$, the use of condom $(\mathrm{OR}=1,34$; $95 \% \mathrm{CI}=1,18-1,52)$, and less initiation in doing the sex for the first time $(\mathrm{OR}=0,66 ; 95 \% \mathrm{CI}=0,54-0,83)$ [26]. Similarly, research conducted by Suwarni and Selviana resulted that the initiation to do premarital sex was less if there were the family role and school role in adolescence sex education [2].

The adolescence intercourse behavior was influenced by the adolescence perception through the susceptibility to the health, spiritual, and individual character [27]. IMB intervention could improve the susceptible perception intercourse behavior to the health of the adolescence. In additional, it was supposed to the IMB intervention, so the adolescence would not do intercourse before married.

The behavior to reduce the Low health risk behavior (for example, delaying the intercourse) could be done if they understand the real and serious consequences of those risk behaviors (e.g. AIDS and death) and their thought about the risk which made them avoiding the behavior (avoiding to do intercourse),thus it could lower the risk for their health [27]. Based on this research, the adolescence who was applied IMB intervention could get the right information about the risk and the offender to make them understand about the negative impact of the risk behavior. The information also improved the adolescence's motivation not to do the risk behavior and they also had the skill to refuse in doing the premarital sex. IMB intervention model was suitable to be used in changing the risk behavior [14]. Furthermore, the school-based intervention through IMB model could be the primary prevention in adolescence premarital sex behavior intention.

IMB intervention can be applied through the integration of the subject in the schools (for example, religious subject, civic education, biology (science), and physical education), thus it is not needed to give extra time for sex education or reproductive health. The integration needs the role of school to improve the adolescence information, motivation, and skill to refuse to do premarital sex.

\subsection{Limitation}

This research focusses on the adolescence information, motivation, and skill to refuse or delay to do the premarital sex among adolescence through quantitative and self-reported measurement. The further 
research is needed to describe more about information, motivation, and skill through qualitative method to get more data. Besides, it is also needed to involve the parents'role to make IMB model being consistent and continued primary prevention on adolescence premarital sex.

\section{CONCLUSION}

IMB model intervention could be preventing intention's adolescence in doing premarital sex. Furthermore, IMB model as the primary prevention is effective to prevent the premarital sex behavior through the integrated subjects in the school. It is needed the family and school support to IMB model in preventing the adolescence to do the premarital sex.

\section{ACKNOWLEDGEMENTS}

The authors wish to express gratefulness and thanks to the all of participation in this research. The authors also grateful to authors/editors/publisher of all those articles, journals, and books from where the literature for this article has been reviewed and discussed.

\section{REFERENCES}

[1] UNICEFT Indonesia, "Brief of respond on HIV AIDS," Jakarta, 2012.

[2] L. Suwarni and Selviana, "Adolescence's Premarital Sex Initiation and Its determinants," KEMAS UNNES, vol/issue: 10(2), 2015.

[3] M. Abdullahi and A. Umar, "Consequences of Pre-Marital Sex among the Youth a Study of University of Maiduguri," Journal of Humanities and Social Science, vol/issue: 10(1), pp. 10-17, 2013.

[4] A. K. Blanc and A. A. Way, "Sexual behavior and contraceptive knowledge and use among adolescent in developing countries," Studies Fam Plan, vol/issue: 29(2), pp. 106-116, 1998.

[5] A. K. Driscoll, et al., "Nonmarital childbearing among adult women," Journal of Mariage and Family, vol/issue: 61(1), pp. 178-187, 1999.

[6] J. Greenberg, et al., "Age at first coitus: A marker for risky sexual behavior in women," Sexually Transmitted Disease, vol/issue: 19(6), pp. 331-334, 1992.

[7] J. Manlove, et al., "Pathways from family religiosity to adolescent sexual activity and contraceptive use," Perspectives on Sexual \& Reproductive Health, vol. 40, pp. 105-117, 2008.

[8] J. W. Santrock, “A Topical Approach to Life-Span Development,” 6th ed. McGraw-Hill Companies, 2012.

[9] J. D. Fisher, et al., "Information-motivation-behavioral skills model-based HIV risk behavior change intervention for inner-city high school youth," Health Psychol, vol/issue: 21(2), pp. 177-186, 2002.

[10] M. Kaufman, et al., "Health Behavior Change Models for HIV Prevention and AIDS Case: Practical Recommendations for A Multi-Level Approach," Journal of Aquired Immune Deficiency Syndromes, vol. 66, pp. S250-S258, 2014

[11] M. L. Ybarra, et al., "Examining the Applicability of the IMB Model in Predicting Condom Use Among Sexually Active Secondary School Students in Mbarara, Uganda," Aids Behav, vol/issue: 17(3), pp. 1116-1128, 2013.

[12] S. C. Kalichman, et al., "Health information on the Internet and people living with HIV/AIDS: Information evaluation and coping styles," Health Psychology, vol. 25, pp. 205-210, 2006.

[13] Y. Cai, et al., "Predictors of consistent condom use based on Information-Motivation-Behavior Skill (IMB) model among students in three coastal cities in China," BMC Infectious Diseases, vol. 13, pp. 262, 2013.

[14] Fisher J. D., et al., "Changing AIDS risk behavior: Effects of an intervention emphasizing AIDS risk reduction information, motivation, and behavioral skills in a college student population," Health Psychology, vol. 15, pp. 114-123, 1996.

[15] Scott S. L. A., et al., "Predicting condom use among STD clinic patients using the Information - MotivationBehavioral Skills (IMB) model," J Health Psychol, vol. 15, pp. 1093-102, 2010.

[16] Walsh J. L., et al., "Predicting condom use using the Information-Motivation-Behavioral Skills (IMB) model: a multivariate latent growth curve analysis," Ann Behav Med, vol. 42, pp. 235-244, 2011.

[17] Fisher C. M., "J Are Information, Motivation, and Behavioral Skills Linked with HIV-Related Sexual Risk among Young Men Who Have Sex with Men?” HIV AIDS Soc Serv, vol. 10, pp. 5-21, 2011.

[18] M. Bazargan, et al., "Using the Information-Motivation-Behavioral Model to Predict Sexual Behavior among Underserved Minority Youth," Journal of School Health, vol/issue: 80(6), pp. 287-295, 2010.

[19] Z. Bahrami and F. Zarani, "Application of the information-motivation and behavioral skill (IMB) model in risky sexual behaviors amongst male students," Journal of Infection and Public Health, vol/issue: 8(2), pp. 207-213, 2015 .

[20] D. Wight, et al., "Limits of teacher delivered sex education: Interim behavioral outcomes from randomised trial," BMJ, vol. 324, pp. 1-6, 2002.

[21] J. S. Tukan, "Methods of Sexual Education,” Jakarta, Erlangga, 1993.

[22] V. P. Ebhohimhen, et al. "A systematic review of school-based sexual health interventions to prevent STI/HIV in SubSaharan Africa," BMC Public Health, vol/issue: 8(4), pp. 1-13, 2008. 
[23] A. M. Jones, et al., "A systematic review of the role of school-based healthcare in adolescent sexual reproductive and mental health," Systematic Review, vol. 1, pp. 49, 2012.

[24] De La Rue L, et al., "School-based Interventions to Reduce Dating and Sexual Violence: A Systematic Review," Campbell Systematic Reviews, vol. 7, 2014.

[25] D. M. Denno, et al., "Effective strategies to provide adolescent sexual and reproductive health services and to increase demand and community support," Journal of Adolescent Health, vol. 56, pp. s22-241, 2014.

[26] Fonner V. A., et al., "School Based Sex Education and HIV Prevention in Low and MiddleIncome Countries: A Systematic Review and MetaAnalysis," PLoS ONE, vol/issue: 9(3), 2014.

[27] M. Ghaffari, et al., "Premarital sexual intercourse-related individual factors among Iranian adolescents: A Qualitative study," Iran Red Crescent Med J, vol/issue: 18(2), 2016. 